\title{
Invited Commentary on Genetically Modified Mosquitoes for Population Control of Pathogen-Transmitting Wild-Type Mosquitoes
}

\author{
Leroy Versteeg $^{1} \cdot$ Qian Wang $^{1} \cdot$ Coreen M. Beaumier ${ }^{1}$
}

Published online: 2 February 2016

(C) Springer International Publishing AG 2016

Keywords Genetically modified mosquitoes $\cdot$ Aedes . Aegypti $\cdot$ Albopictus $\cdot$ Pathogen control $\cdot$ Sterile insect technique

Mosquito-borne diseases plague many areas throughout the world and are a significant cause of mortality and morbidity. Many species of these vectors can carry human pathogens, including the Aedes, Culex, and Anopheles genera of mosquitoes. These pathogens also range from viruses, such as Zika, dengue, and chikungunya, to parasites like malaria-causing Plasmodium spp. Additionally, mosquitoes carry veterinary health threats including Dirofilaria immitis (canine heartworm), in addition to those which infect both humans and animals like West Nile Virus and Eastern Equine Encephalitis Virus. Despite significant efforts, most of these maladies throughout the world are still without licensed vaccines or treatment to combat them. Alternate methods of prevention are also being investigated.

One strategy that is gaining interest is using genetically modified mosquitoes (GMMs) to control mosquito populations in the field and in particular, the Sterile Insect Technique (SIT) is making significant headway. Originally proposed by Knipling in the 1950s, SIT is a method to decrease the mosquito population by releasing sterile male mosquitoes into the target area. Once these male mosquitoes are in

Leroy Versteeg and Qian Wang contributed equally to this work.

Coreen M. Beaumier

beaumier@bcm.edu

1 Sabin Vaccine Institute and Texas Children's Hospital Center for Vaccine Development, National School of Tropical Medicine, Baylor College of Medicine, Houston, TX, USA

the field, they will mate with female mosquitoes from the same species and the females will be unable to produce fertile offspring. It is believed that by releasing sterile male mosquitoes, the target population in that released area is suppressed [1]. The SIT method has previously been effective and successful in insect population suppression or eradication for several major pests such as the screwworm fly (Callitroga hominivorax), Mediterranian fruit fly (Ceratitis capitata), and the Mexican fruit fly (Anastrepha ludens) [2, 3].

In a conventional mosquito SIT approach, the male mosquitoes are sterilized by exposing them to either radiation or sterilizing chemicals, resulting in large-scale DNA-damage or dominant lethality in the sperm $[4,5]$. Since the 1960s, this method of mosquito control has been most widely field tested and has been used in the USA and other countries to affect a variety of mosquito species such as Aedes aegypti [6, 7], Aedes albopictus [8], Culex quinquefasciatus [9], Culex tarsalis [10], Anopheles albimanus [11], Anopheles culicifacies [12], and Anopheles quadrimaculatus [13]. The outcomes are of mixed success, as suppressed mosquito populations were observed in some studies but not in others. Although release sites and conditions contributed to the inconsistent outcomes, the main challenges of the conventional SIT include leak of female mosquitoes into the intended all male population of GMMs, the difficulties of achieving high rates of sterility and reduced competitiveness in the field of the released sterilized male mosquitoes $[4,14]$.

Recent genetic technologies provide significant improvement to conventional SIT by insertion of synthetic genes into the mosquito genome to achieve a specific inheritable lethal effect. One approach, which is currently the most advanced, is the release of insects carrying a dominant lethal (RIDL) genetic system $[15,16]$, developed by Oxitec, UK. Similar to the conventional SIT, this approach focuses on population suppression by killing the female heterozygous offspring when 
homozygous males carry the lethal genes and mate with the wild females. Since this gene modification is either femaletargeted and/or stage-specific, the competitiveness of the males is less compromised [5, 17-19].

Oxitec's technology is currently in various field trials throughout the world and though they have seen some success, they have also been met with various regulatory and public relations hurdles as genetically modified organisms often are met with public wariness. For example, the first field trial of Aedes aegypti RIDL strain OX513A in the Grand Cayman Islands showed that release of transgenic male mosquitoes was able to reduce target population by $80 \%$ [10]. However, when these results Oxitec's were announced at the 2010 American Society of Tropical Medicine and Hygiene (ASTMH) yearly conference, some found it concerning that the international community was not made aware of the ongoing trials until Oxitec's findings were publicly presented $[20,21]$ and feared that this lack of widespread publicity may hurt efforts in trying to gain the public's support in furthering the GMM field. However, Oxitec claimed that intentions and details of the trials were made available to the islands' populations and they worked with the islands' Mosquito Research and Control Unit (MRCU) to conduct the studies [21].

Oxitec also has engaged Brazil for GMM trials. These trials have been ongoing in the towns of Jazeiro and Jacobina and are regulated by the National Biosafety Policy (PNB) in Brazil who is advised by the National Biosafety Technical Commission (CTNBio), a commission created by the PNB and which sets safety standards regarding trials such as these [22]. CTNBio has previously approved the commercial release of the Oxitec mosquitoes. However, as this is associated with the health sector, approval from Agência Nacional de Vigilância Sanitária (ANVISA) is required [22]. Since there is no precedent for GMM in Brazil, the Oxitec technology is still under consideration by ANVISA [23]. The preliminary data from field trials in several Brazil neighborhoods showed consistent reduction of Aedes aegypti populations: a project in the town of Jacobina, Bahia, has reduced the wild population of Aedes aegypti in the Pedra Branca neighborhood by $92 \%$ and two other projects in the city of Juazeiro, neighborhood of Itaberaba, the reduction was $94 \%$ and Mandacaru, $99 \%$ [24].

In 2010, Oxitec received permission from the National Biosafety Board, Ministry of Natural Resources and Environment (NRE) of Malaysia for a Marked Release and Recapture (MRR) field trial which was conducted from October, 2010 to January, 2011. In an effort to inform the population of the intent to conduct the trials, the Malaysian government published the trials on their website but received little public response. As a result, they engaged nine governmental organizations to provide feedback on the trials, which they also displayed on the website. Following this, a question and answer session was held with the media as well as public briefings. The field trials were conducted along with the Institute for Medical Research (IMR), a federal institute [25]. In the following trial in Malaysia, the OX513A mosquitoes showed similar field longevity with a comparable maximum dispersal but lower median and mean dispersal to an unmodified counterpart; however, the lower dispersal capacity was adequate for the use in use of sterile-male release program in an uninhabited area [26].

In collaboration with the Gorgas Institute in Panama, Oxitec undertook field studies with the GMMs in the Arraiján District, a suburb of Panama City, Panama in 2014. This trial commenced after approval from the Ministries of Agricultural Development and Commerce and Industry as recommended by the National Biosafety Committee of Panama. In the most recently completed field trial in Panama, Oxitec reported over $90 \%$ in the local reduction of the Aedes aegypti mosquitoes 6-month post release [27].

Most recently, Oxitec has sought approval to conduct a field trial with GMM's in the USA in Key Haven, Florida. An Investigational New Animal Drug (INAD) file has been submitted to the FDA and the FDA is consulting with other federal agencies, CDC and EPA, for a full assessment and evaluation. Though the FDA's decision is still pending, since Oxitec has publically announced its INAD submission, the agency is able to acknowledge it to the public and will publish its draft environmental assessment on www.regulations.gov/. Once posted, it will be open for comment [28]. There is already public comment on the Oxitec docket on www.regulations.gov/ with a mix of positive and negative opinions.

Although RIDL system has achieved significant success, the inherent self-limiting trait that the lethal genes disappear quickly in subsequent generations requires consistent release of large number of genetically modified males [15]. A second genetic modification approach is developed using gene-driven mechanism [29]. One method is to use selfish genes such as homing endonuclease genes (HEGs). In a HEG heterozygous offspring mosquito, this type of gene is able to copy itself and converting the heterozygote to a homozygote $[5,15,29,30]$. By linking specific target genes with HEGs, the mosquitoes can be engineered with desired phenotypes, such as reduced vector competence vector [31] or high sterility [32]. HEGs have been successfully introduced into Anopheles gambiae [31,33] and Aedes aegypti $[34,35]$; however, field trials of HEG-modified mosquitoes are yet to be carried out.

\section{Compliance with Ethical Standards}

Conflict of Interest The authors declare that they have no competing interests.

Human and Animal Rights and Informed Consent This article does not contain any studies with human or animal subjects as performed by any of the authors. 


\section{References}

1. Zhang D et al. Combining the sterile insect technique with wolbachia-based approaches: II - a safer approach to aedes albopictus population suppression programmes, designed to minimize the consequences of inadvertent female release. PLoS One. 2015;10(8), e0135194.

2. Knipling EF. Sterile-male method of population control. Science. 1959;130(3380):902-4.

3. Lees RS, Gilles JR, Hendrichs J, Vreysen MJ, Bourtzis K. Back to the future: the sterile insect technique against mosquito disease vectors. Curr Opin Insect Sci. 2015;10:156-62.

4. Dame DA et al. Historical applications of induced sterilisation in field populations of mosquitoes. Malar J. 2009;8 Suppl 2:S2.

5. McGraw EA, O'Neill SL. Beyond insecticides: new thinking on an ancient problem. Nat Rev Microbiol. 2013;11(3):181-93.

6. McDonald PT, Hausermann W, Lorimer N. Sterility introduced by release of genetically altered males to a domestic population of Aedes aegypti at the Kenya coast. Am J Trop Med Hyg. 1977;26(3):553-61.

7. Ogah F, Juma N. A field trial of suppression of Aedes aegypti population by releasing sterile males into a domestic population. Parassitologia. 1977;19(1-2):73-8.

8. Bellini R et al. Pilot field trials with Aedes albopictus irradiated sterile males in Italian urban areas. J Med Entomol. 2013;50(2): 317-25.

9. Patterson RS, Lowe RE, Smittle BJ, Dame DA, Boston MD, Cameron AL. Release of radiosterilized males to control Culex pipiens quinquefasciatus (diptera: culicidae). J Med Entomol. 1977;14(3):299-304.

10. Reisen WK, Milby MM, Asman SM, Bock ME, Meyer RP, McDonald PT, et al. Attempted suppression of a semi-isolated Culex Tarsalis Population by the release of irradiated males: a second experiment using makes from a recently colonized strain. Mosquito News. 1982;42(4):565-75.

11. Lofgren CS et al. Release of chemosterilized males for the control of Anopheles albimanus in El Salvador. 3. Field methods and population control. Am J Trop Med Hyg. 1974;23(2):288-97.

12. Reisen WK, Baker R, Sakai RK, Mahmood F, Rathor HR, Raana K, et al. Anopheles culicifacies Giles: mating behavior and competitiveness in nature of chemosterilized males carrying a genetic sexing system. Ann Entomol Soc Am. 1981;74(4):395-401.

13. Weidhaas DE, Schmidt CH. Field studies on the release of sterile males for the control of Anopheles Quadrimaculatus. Mosquito News. 1962;22:283-91.

14. Benedict MQ, Robinson AS. The first releases of transgenic mosquitoes: an argument for the sterile insect technique. Trends Parasitol. 2003;19(8):349-55.

15. Alphey L. Genetic control of mosquitoes. Annu Rev Entomol. 2014;59:205-24.

16. Thomas DD et al. Insect population control using a dominant, repressible, lethal genetic system. Science. 2000;287(5462):2474-6.

17. Lee HL et al. Mating compatibility and competitiveness of transgenic and wild type Aedes aegypti (L.) under contained semi-field conditions. Transgenic Res. 2013;22(1):47-57.
18. Patil PB et al. Mating competitiveness and life-table comparisons between transgenic and Indian wild-type Aedes aegypti L. Pest Manag Sci. 2015;71(7):957-65.

19. Wise de Valdez MR et al. Genetic elimination of dengue vector mosquitoes. Proc Natl Acad Sci U S A. 2011;108(12):4772-5.

20. Enserink, M. GM Mosquito Release in Malaysia Surprises Opponents and Scientists-Again. Science Insider 2011 12/21/ 15]; Available from: http://news.sciencemag.org/asia/2011/01/gmmosquito-release-malaysia-surprises-opponents-and-scientists $\%$ E2\%80\%94again.

21. Subbaraman N. Science snipes at Oxitec transgenic-mosquito trial. Nat Biotechnol. 2011;29:9-11.

22. Oxitec. Dúvidas Frequentes. 2013 [cited 12/21/15; Available from: http://br.oxitec.com/faq/.

23. LEITE, M. Anvisa mata-mosquito. 2015; Available from: http:// www.cff.org.br/noticia.php?id=3068.

24. Thompson, T. PRESS RELEASE: Oxitec do Brasil opens its first mosquito production unit to fight the dengue vector, Aedes aegypti. 2014 12/21/15]; Available from: http://www.oxitec.com/pressrelease-oxitec-do-brasil-opens-its-first-mosquito-production-unitto-fight-the-dengue-vector-aedes-aegypti.

25. Institute for Medical Research, M.o.H., Malaysia. GM Aedes aegypti Research. 2013 12/21/15]; Available from: http://www. imr.gov.my/en/component/content/article?id=1119.

26. Lacroix $\mathrm{R}$ et al. Open field release of genetically engineered sterile male Aedes aegypti in Malaysia. PLoS One. 2012;7(8), e42771.

27. T, T. Oxitec mosquito trial success in Panama. 2015 12/21/15]; Available from: http://www.oxitec.com/oxitec-newsletter-march2015.

28. Administration, U.S.F.a.D. Oxitec Mosquito. 2015 12/21/15]; Available from: http://www.fda.gov/AnimalVeterinary/ DevelopmentApprovalProcess/GeneticEngineering/ GeneticallyEngineeredAnimals/ucm446529.htm.

29. Sinkins SP, Gould F. Gene drive systems for insect disease vectors. Nat Rev Genet. 2006;7(6):427-35.

30. Burt A. Site-specific selfish genes as tools for the control and genetic engineering of natural populations. Proc Biol Sci. 2003;270(1518):921-8.

31. Windbichler $\mathrm{N}$ et al. Homing endonuclease mediated gene targeting in Anopheles gambiae cells and embryos. Nucleic Acids Res. 2007;35(17):5922-33.

32. Deredec A, Godfray HC, Burt A. Requirements for effective malaria control with homing endonuclease genes. Proc Natl Acad Sci U S A. 2011;108(43):E874-80.

33. Klein TA et al. Infertility resulting from transgenic I-PpoI male Anopheles gambiae in large cage trials. Pathog Glob Health. 2012;106(1):20-31.

34. Kistler KE, Vosshall LB, Matthews BJ. Genome engineering with CRISPR-Cas9 in the mosquito Aedes aegypti. Cell Rep. 2015;11(1):51-60.

35. Traver BE, Anderson MA, Adelman ZN. Homing endonucleases catalyze double-stranded DNA breaks and somatic transgene excision in Aedes aegypti. Insect Mol Biol. 2009;18(5): $623-33$. 